\title{
Dialysis Options for End-Stage Renal Disease in Older People
}

\author{
Edwina A. Brown ${ }^{\text {a Lina Johansson }}{ }^{b}$ \\ a Imperial College Kidney and Transplant Centre, Hammersmith Hospital, London, and ${ }^{\mathrm{b}}$ Imperial College London, UK
}

\section{Key Words}

End-stage renal disease - Dialysis options - Quality of life •

Haemodialysis · Peritoneal dialysis

\begin{abstract}
The numbers of older patients requiring dialysis therapy is rising, reflecting the ageing of the general population. Older dialysis patients have a tendency to present later for dialysis, have a higher number of comorbid conditions, are at higher risk of cognitive dysfunction and have increased levels of frailty. These are all barriers to home dialysis therapy so hospital haemodialysis (HD) is the predominant dialysis modality for older patients. Evidence suggests, however, that home treatment with peritoneal dialysis (PD) intrudes less into the life of older patients than hospital HD. Assisted PD is available in some countries and this enables more older patients to be treated in their own homes. Adjustments to patient education also need to be made to accommodate the barriers to learning and decision-making that often exist in older people.

Copyright $\odot 2011$ S. Karger AG, Basel
\end{abstract}

\section{Dialysis in Older People: A Growing Population}

Dialysis is now considered routine care for the treatment of end-stage renal disease in elderly patients, many of whom have a high co-existent disease burden. In this patient group, dialysis is likely to be for life, with only $15 \%$ of all adult transplantations taking place in those aged $\geq 65$ years in the US in 2008 [1]. Twenty-five years ago, $45.1 \%$ of UK nephrologists responding to a survey would not offer renal replacement therapy to a 50 -year-old man with ischaemic heart disease [2]. In contrast, 15 years later, dialysis was available in the UK for high-risk patients (higher age, severe comorbidities and dependent in relation to functional status) despite a low 1-year survival of $19.2 \%$ [3]. Patient's advancing age and comorbid status no longer influences nephrologists' decision to initiate dialysis [4].

The number of older people requiring dialysis can only increase. Older people form the largest growing segment of the dialysis population and the prevalence of chronic kidney disease increases with age. In the UK, from 2005 to 2008, the dialysis population of adults aged $\geq 65$ years grew by $29 \%$ compared to only $16 \%$ in those aged $18-65$ years $[5,6]$. A similarly high growth rate in older people on dialysis in the US was seen from 1992 to 1995, after which it has steadily been declining to a plateau with a current rate similar to those aged 20-64 years (11-12\%). The oldest old (85 years and over), however, have a high growth rate of $16 \%$ [1].

Dialysis for the older and frailer individual is a comparatively new treatment option. Proposing dialysis appears to be limited only by medical or social reasons as opposed to age alone. It is also important to note that the vast majority (94\%) of octogenarians opt for treatment where dialysis was deemed appropriate by the renal team [7]. Only $12.5 \%$ of those aged $\geq 80$ years would not recommend dialysis to patients of the same age [8].

\section{KARGER \\ Fax +4161306 1234 E-Mail karger@karger.ch} www.karger.com

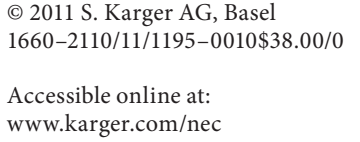


Table 1. Percentages of prevalent patients aged $\geq 65$ years on different dialysis modalities in the US [1], UK [6], Australia and New Zealand [16] and Canada [17] for 2008

\begin{tabular}{lllllrrr}
\hline Country & $\begin{array}{l}\text { Centre } \\
\text { HD }\end{array}$ & $\begin{array}{l}\text { Satellite } \\
\text { HD }\end{array}$ & $\begin{array}{l}\text { Home } \\
\text { HD }\end{array}$ & $\begin{array}{l}\text { Centre HD }+ \\
\text { satellite HD }+ \\
\text { home HD }\end{array}$ & CAPD & $\begin{array}{c}\text { APD } \\
\text { CAPD + } \\
\text { APD + } \\
\text { aPD }\end{array}$ \\
\hline USA & & & 1 & 95 & 2 & 3 & 5 \\
Canada & 48 & 38 & 1 & 87 & 9 & 4 & 15 \\
UK & 27 & 48 & 4 & 79 & 10 & 10 & 20 \\
Australia & 36 & 16 & 8 & 60 & 27 & 12 & 39 \\
New Zealand & & & & & 10 \\
\hline
\end{tabular}

$\mathrm{HD}=$ Haemodialysis $\mathrm{PD}$ = peritoneal dialysis; $\mathrm{CAPD}=$ continuous ambulatory $\mathrm{PD} ; \mathrm{APD}=$ automated PD; $\mathrm{aPD}=$ assisted PD.

\section{Features of the Older Dialysis Group}

As a population, older dialysis patients have a tendency to present later for dialysis [9], have a higher number of comorbid conditions, are at higher risk of cognitive dysfunction [10] and have increased levels of frailty [11], all combined with potential sensory impairments [12]. Socially, this may lead to increased difficulty coping at home due to functional and psychological dependencies [13] or alternatively, patients may sometimes be carers themselves [14]. It is perhaps inevitable that the propensity for such limitations should curtail the self-care dialysis treatment options available to older people in the absence of support.

\section{Dialysis Options for the Elderly: An International Comparison}

Dialysis for older people is available as a treatment predominantly in developed countries [15]. Even within these different geographical locations, there are varying trends on how older people dialyse as demonstrated in table 1 .

Centre-based haemodialysis (HD) is the predominant treatment in the older prevalent dialysis population but ranges from 52\% in New Zealand [16] to $94 \%$ in the US [1]. There are obvious differences between the two countries in relation to practicalities of undertaking HD due to the differences in geographical accessibility to dialysis centres and reimbursement [18], leading to circumstances where home therapies may be unduly favoured. Nonetheless, the data suggest that a higher proportion of older people may have the potential to be on a home-based treatment. This is reflected in the proportion of older pa- tients on peritoneal dialysis (PD) and home HD in New Zealand (39 and 8\%) and Australia (20 and 4\%) [16] compared to the UK (13 and 1\%) [6] and in particular, the US (5 and 1\%) [1].

\section{Survival and Quality of Life in Older People on Dialysis}

Modality (PD compared to in-centre HD) did not affect survival of 14,512 older Canadian patients between 1990 and 1999 when adjusting for several characteristics, e.g. gender and comorbid conditions [19]. A similar finding was reported by the North Thames Dialysis Study in a sample of 123 incident patients $\geq 70$ years measuring survival at 1 year [20]. In fact, there have been several reports of reasonable survival for older people on both modalities [20-22]. Higher mortality rates were, however, seen in incident older diabetic PD patients from the US in the first 3 months of treatment and between months 6-12 in a 1-year study [23]. These findings may reflect dialysis populations in countries with low $\mathrm{PD}$ utilisation.

Quality of life (QOL) is probably a more pertinent outcome in assessing the different and most usually life-long dialysis options for the elderly. Two studies have focused on QOL in the elderly, comparing HD and PD. The North Thames Dialysis Study found no difference between QOL in patients $>70$ years old on PD or HD [24]. In the more recent BOLDE study, we conducted multiple QOL assessments and found that older HD patients experienced more illness and treatment intrusion compared to those on PD even after adjustment for multiple confounders, e.g. comorbidities [25]. When considering home dialysis in older people, however, the impact on caregivers is also an important consideration. Worse Mental Component 
Summary scores from the SF-36 were found in caregivers of elderly PD patients compared to caregivers of elderly HD patients [26].

\section{Home-Based Dialysis Solutions for the Elderly}

The declining independence levels seen in older people make HD an attractive option where dialysis can be managed by trained specialists. Equally, if not more appealing is the ability to support older patients and their carers within their homes. Patients incapable of self-care PD can be supported through assisted PD (aPD), where trained staff provide daily dialysis assistance either in nursing homes or in patients' homes.

There are several reports of successful PD for nursinghome residents $[27,28]$. In areas where aPD is available to support patients within their homes, $75 \%$ of those who chose $\mathrm{PD}$ received aPD compared to self-care $\mathrm{PD}$. This is perhaps unsurprising as $81 \%$ of an incident end-stage renal disease population in Ontario, Canada, had at least one medical or social barrier to self-care PD [29]. Home HD is also offered to nursing-home residents in the US [30].

\section{The Largest and Longest Experience of aPD with Excellent Survival Results}

A recent report from the French Peritoneal Dialysis Registry for 1,613 patients aged $\geq 75$ years commencing on PD between 2000 and 2005 showed that $76 \%$ needed assistance by community private nurses to perform the dialysis exchanges [22]. The nurse-assisted patients had a median survival of 27.1 months which compares favourably to the $50 \%$ survival of 24 months for all new patients on renal replacement therapy $>75$ years old in the UK Renal Registry [6]. Canadian data also show that adverse events (e.g. hospitalisations and death) were no different between patients on aPD and other dialysis modalities in older people, although this was compared only in small numbers [29]. Supporting dialysis therapies at home therefore appears to be a viable dialysis option for the elderly who may experience difficulties in undertaking self-care treatments or attending dialysis facilities.

\section{Modality Education and OIder People}

As we have discussed above, many older patients could be eligible for home dialysis options, particularly if assis- tance is available. During the predialysis phase while in renal clinics, they should be provided with education to enable them to participate in the decision regarding the most appropriate dialysis modality for them. If we consider the wider context of governmental goals for encouraging health benefits for the UK population, involvement in treatment decisions is certainly a focal point [31]. The choice of dialysis modality is a prime example where the patient's personal values should be matched with the medical characteristics of the treatment in order to maximize achievable QOL. Even in locations where dialysis modality options exist, these may not always be presented in an appropriate manner to the older patient. Written information from renal units is often complex and difficult to understand [32], hindering decision-making in a group already vulnerable to comprehension errors [33]. Increasing age was associated with fear that home-based treatments were substandard compared to in-centre dialysis in a sample of HD patients [34]. Education is therefore critical in clarifying misconceptions. Older people are more likely to prefer the healthcare team to make treatment decisions, although there is wide variation in this $[35,36]$. There is also evidence that healthcare teams will respond by taking dialysis treatment decisions on behalf of older patients [36]. Therefore, there is a real risk within this patient group that the modality favoured by the renal team becomes the treatment of choice.

\section{Conclusions}

Increasingly, supported and home based permutations of current dialysis modalities are being considered and used successfully in older people who have barriers to self-care. Assisted home therapies (PD and HD) would enable older people to be treated in a manner that may be best suited to their needs and caregivers would be relieved from the burden that often accompanies the role. Unfortunately, dialysis options for the elderly largely depend on what alternatives are available within the residing country. Providing a real choice of modality not only requires commitment and support at government level but, in addition, requires an appreciation by all those involved in educating patients of the barriers to learning that older people face and adjust their education accordingly.

\section{Disclosure Statement}

The authors have no conflicts of interest to declare. 


\section{References}

1 United States Renal Data System: US Renal Data System, USRDS 2010 Annual Data Report: Atlas of End-Stage Renal Disease in the United States. Bethesda, National Institutes of Health, National Institute of Diabetes and Digestive and Kidney Diseases, 2010.

$\checkmark 2$ Challah S, Wing AJ, Bauer R, Morris RW, Schroeder SA: Negative selection of patients for dialysis and transplantation in the United Kingdom. Br Med J (Clin Res Ed)1984;288: 1119-1122.

-3 Chandna SM, Schulz J, Lawrence C, Greenwood RN, Farrington K: Is there a rationale for rationing chronic dialysis? A hospital based cohort study of factors affecting survival and morbidity. BMJ 1999;318:217-223.

-4 Kee F, Patterson CC, Wilson EA, McConnell JM, Wheeler SM, Watson JD: Stewardship or clinical freedom? Variations in dialysis decision making. Nephrol Dial Transplant 2000; 15:1647-1657.

5 Ansell D, Feest T, Hodsman A, Rao R, Tomson C, Udayaraj U, Williams A, Warwick GE. UK Renal Registry Report 2006. Bristol, UK Renal Registry, 2007.

6 Ansell D, Castledine C, Feehally J, Fogarty D, Ford D, Inward C, Tomson C, Warwick G, Webb L, Williams AE. UK Renal Registry Report 2009. Bristol, UK Renal Registry, 2010.

-7 Joly D, Anglicheau D, Alberti C, Nguyen AT, Touam M, Grunfeld JP, Jungers P: Octogenarians reaching end-stage renal disease: Cohort study of decision-making and clinical outcomes. J Am Soc Nephrol 2003;14: 1012-1021.

$\checkmark 8$ Schaefer K, von Herrath D, Faust J, Röhrich $B$ : The very elderly dialysis patient: indication and discontinuation of dialysis. Int Urol Nephrol 2002;34:573-576.

\9 Roderick P, Jones C, Drey N, Blakeley S, Webster P, Goddard J, Garland S, Bourton L, Mason J, Tomson C: Late referral for endstage renal disease: a region-wide survey in the south west of England. Nephrol Dial Transplant 2002;17:1252-1259.

$\checkmark 10$ Murray AM, Tupper DE, Knopman DS, Gilbertson DT, Pederson SL, Li S, Smith GE, Hochhalter AK, Collins AJ, Kane RL: Cognitive impairment in hemodialysis is common. Neurology 2006;67:216-223.

- 11 Johansen KL, Chertow GM, Jin C, Kutner NG: Significance of frailty among dialysis patients. J Am Soc Nephrol 2007;18:29602967.
12 Chiu E, Markowitz SN, Cook WL, Jassal SV: Visual impairment in elderly patients receiving long-term hemodialysis. Am J Kidney Dis 2008;52:1131-1138.

13 Cook WL, Jassal SV: Functional dependencies among the elderly on hemodialysis. Kidney Int 2008;73:1289-1295.

14 The Information Centre for Health and Social Care: Survey of Carers in households in England 2009/10. Information Centre for Health and Social Care, 2010.

15 Grassmann A, Gioberge S, Moeller S, Brown G: ESRD patients in 2004: global overview of patient numbers, treatment modalities and associated trends. Nephrol Dial Transplant 2005;20:2587-2593.

16 MacDonald S, Excell L, Livingston BE: ANZDATA Registry 2009. Adelaide, Australia and New Zealand Dialysis and Transplant Registry, 2009.

17 Canadian institute for Health Information: Treatment of end-stage organ failure in Canada, 1999 to 2008-CORR 2010 Annual Report (Ottawa, Ont.: CIHI 2010), 2010.

18 Just PM, de Charro FT, Tschosik EA, Noe LL, Bhattacharyya SK, Riella MC: Reimbursement and economic factors influencing dialysis modality choice around the world Nephrol Dial Transplant 2008;23:23652373.

19 Jassal SV, Trpeski L, Zhu N, Fenton S, Hemmelgarn B: Changes in survival among elderly patients initiating dialysis from 1990 to 1999. Can Med Assoc J 2007;177:1033-1038.

20 Lamping DL, Constantinovici N, Roderick P, Normand C, Henderson L, Harris S, Brown E, Gruen R, Victor C: Clinical outcomes, quality of life, and costs in the North Thames Dialysis Study of elderly people on dialysis: a prospective cohort study. Lancet 2000;356: 1543-1550.

21 Kurella M, Covinsky KE, Collins AJ, Chertow GM: Octogenarians and nonagenarians starting dialysis in the United States. Ann Intern Med 2007;146:177-183.

-22 Castrale C, Evans D, Verger C, Fabre E, Aguilera D, Ryckelynck JP, Lobbedez T: Peritoneal dialysis in elderly patients: report from the French Peritoneal Dialysis Registry (RDPLF). Nephrol Dial Transplant 2010;25: 255-262.

23 Winkelmayer WC, Glynn RJ, Mittleman MA, Levin R, Pliskin JS, Avorn J: Comparing mortality of elderly patients on hemodialysis versus peritoneal dialysis: a propensity score approach. J Am Soc Nephrol 2002;13:23532362.

-24 Harris SA, Lamping DL, Brown EA, Constantinovici N: Clinical outcomes and quality of life in elderly patients on peritoneal dialysis versus hemodialysis. Perit Dial Int 2002;22:463-470
25 Brown EA, Johansson L, Farrington K, Gallagher H, Sensky T, Gordon F, Da Silva-Gane M, Beckett N, Hickson M: Broadening Options for Long-term Dialysis in the Elderly (BOLDE): differences in quality of life on peritoneal dialysis compared to haemodialysis for older patients. Nephrol Dial Transplant 2010;25:3755-3763.

26 Belasco A, Barbosa D, Bettencourt AR, Diccini S, Sesso R: Quality of life of family caregivers of elderly patients on hemodialysis and peritoneal dialysis. Am J Kidney Dis 2006;48:955-963.

27 Anderson JE: Ten years' experience with CAPD in a nursing home setting. Perit Dial Int 1997;17:255-261.

28 Taskapan H, Tam P, LeBlanc D, Ting RH, Nagai GR, Chow SS, Fung J, Ng PS, Sikaneta T, Roscoe J, Oreopoulos DG: Peritoneal dialysis in the nursing home. Int Urol Nephrol 2010;42:545-551.

29 Oliver MJ, Quinn RR, Richardson EP, Kiss AJ, Lamping DL, Manns BJ: Home care assistance and the utilization of peritoneal dialysis. Kidney Int 2007;71:673-678.

30 Reddy NC, Korbet SM, Wozniak JA, Floramo SL, Lewis EJ: Staff-assisted nursing home haemodialysis: patient characteristics and outcomes. Nephrol Dial Transplant 2007;22: 1399-1406.

31 Department of Health: White Paper Equity and Excellence: Liberating the NHS, 2010.

32 Winterbottom A, Conner M, Mooney A, Bekker HL: Evaluating the quality of patient leaflets about renal replacement therapy across UK renal units. Nephrol Dial Transplant 2007;22:2291-2296.

33 Finucane ML, Mertz CK, Slovic P, Schmidt ES: Task complexity and older adults' decision-making competence. Psychol Aging 2005;20:71-84

- 34 McLaughlin K, Manns B, Mortis G, Hons R, Taub K: Why patients with ESRD do not select self-care dialysis as a treatment option. Am J Kidney Dis 2003;41:380-385.

35 Bastiaens H, Van Royen P, Pavlic DR, Raposo V, Baker R: Older people's preferences for involvement in their own care: a qualitative study in primary health care in 11 European countries. Patient Educ Couns 2007;68:3342.

36 Orsino A, Cameron JI, Seidl M, Mendelssohn D, Stewart DE: Medical decision-making and information needs in end-stage renal disease patients. Gen Hosp Psychiatry 2003; 25:324-331 